\title{
Frequency of Vesicoureteral Reflux in Children having Recurrent Urinary Tract Infections
}

\section{Irum Aslam, ${ }^{1}$ Muhammad Asif Siddiqui, ${ }^{2}$ Fatima Zia, ${ }^{3}$ Hafsa Qamar ${ }^{4}$}

\begin{abstract}
Objective: Repeated urinary tract infections are significantly related to anatomical abnormalities of urinary tract. Vesicoureteral reflux is quite common, under diagnosed anatomical abnormality, leads to renal scarring and chronic kidney disease. The objective of the study was to determine the frequency of vesicoureteral reflux in children having repeated urinary tract infections.

Methods: It is cross sectional survey conducted in department of Pediatric Medicine, The Children's Hospital \& Institute of Child Health, Lahore, spanning from 20-5-2014 to 19-11-2014, using non-probability purposive sampling, a total of 140 patients included. Each child was screened and followed with repeated urinary tract infections for frequency of vesicoureteral reflux by detailed clinical examination and relevant investigation as defined in operational definition. To avoid any controversy, all the findings of UTI \& vesicoureteral reflux was assessed by a single consultant. Data was managed using SPSS version 20.

Results: In this study the mean age of all patients was $5.64 \pm 2.35$ years. There were $42(30 \%)$ males and $98(70 \%)$ females in this study with male to female ration $1: 233$. The mean number of episodes of urinary tract infections was $5.82 \pm 1.95$ per years. Frequency of vesicoureteral reflux in these patients was seen in $35(25 \%)$ of the patients. When we stratified the data over age, gender and number of episodes of urinary tract infection we found significant association of vesicoureteral reflux with age groups only ( $\mathrm{p}$-value $<0.05)$ while no association between vesicoureteral reflux versus gender and number of episodes of urinary tract infection ( $p$ value $>0.05)$.

Conclusion: We found significant correlation between vesicoureteral reflux and repeated urinary tract infections. Cases with repeated urinary tract infections should be investigated thoroughly to address underlying cause, in order to prevent renal damage and long-term complications.

Key Words: Paediatric, Urinary tract infections, hydronephrosis, Vesicoureteral reflux

How to Cite: Aslam I, Siddiqui MA, Zia F, Qamar H. Frequency of vesicoureteral reflux in children having recurrent urinary tract infections. Esculapio.2020;16(04): 18-20.
\end{abstract}

DOI: https://doi.org/10.51273/esc20.251644

\section{Introduction}

In $\mathrm{n}$ paediatric population, urinary tract infections (UTI) are commonly seen. Symptoms for UTI include anorexia for fever, lethargy, urinary complaints and vomiting. ${ }^{1} 5 \%$ of children with repeated UTI are at risk of renal damage. ${ }^{2}$ Children with UTI can present with pyelonephritis, urethritis or cystitis. ${ }^{3}$

\begin{tabular}{|c|c|}
\hline $\begin{array}{l}\text { 1. } \quad \text { Irum Aslam } \\
\text { 3. } \quad \text { Fatima Zia } \\
\text { 1,3-4: } P G R \text {, Children's Hospitc }\end{array}$ & $\begin{array}{l}\text { Muhammad Asif Siddiqui } \\
\text { Hafsa Qamar } \\
l \& I C H \text {. }\end{array}$ \\
\hline $\begin{array}{l}\text { Correspondence: } \\
\text { Dr Muhammad Asif Siddiqui } \\
\text { Hospital, Lahore. Email: drmas }\end{array}$ & $\begin{array}{l}\text { Department of Paeds Medicine, Children } \\
\text { ifrmc@gmail.com }\end{array}$ \\
\hline $\begin{array}{l}\text { Submission Date: } \\
\text { 1st Revision Date: } \\
\text { Acceptance Date: }\end{array}$ & $\begin{array}{l}23-08-2020 \\
14-11-2020 \\
14-12-2020\end{array}$ \\
\hline
\end{tabular}

There are different organisms responsible for UTI, Escherichia coli in almost $80 \%$ of total cases. ${ }^{4}$ Other include klebsiella, pseudomonas aeroginosa, enterobacter, and proteus. ${ }^{5}$ UTIs and some congenital abnormalities may cause renal scarring. ${ }^{6}$ Vesicoureteral reflux (VUR) is one of the common congenital anomalies, in which there is backward flow of urine from bladder towards kidneys. VUR is seen in 30 to $50 \%$ of children that are diagnosed with infections of urinary tract. ${ }^{7}$ VUR causes hydronephrosis, increase risk of UTI and in presence of bacterial infection causes pyelonephritis. Kids suffering from hydronephrosis may require daily dose of antibiotic for prevention of UTI or surgical correction. ${ }^{7}$

VUR prevalence is between $22.7 \%$ to $26.4 \%$ in children, suffering from UTI. ${ }^{8}$ Urine tract related 
congenital abnormalities should be suspected and diagnosed promptly in order to prevent irreversible renal damage. Renal ultrasonography, voiding cystourethrography (VCUG), Tc-99m Diethylene- triamine-penta-acetic acid (DTPA) Scan, Dimercaptosuccinic acid Scan (DMSA) are used to diagnose urinary tract congenital abnormalities and extent of renal damage. ${ }^{3}$ Purpose of this study was to see frequency of vesicou-reteral reflux in children with recurrent UTI. Whereas, Urinary tract infection was defined as pure growth of micro-organisms of $>105$ organisms/ml on urine culture. Recurrent urinary tract infection was defined as urinary tract infection twice in 6 months or $\geq 3$ times in 1 year on urine culture. Vesicoureteral reflux was characterized by the retrograde flow of urine from the bladder into ureters or kidneys and was assessed by voiding cystourethrogram (VCUG) in terms of whether being present or not.

\section{Inclusion Criteria}

1. Patients fulfilling operational definition of recurrent urine tract infections.

2. Age between 2 to 10 years

3. Both genders

\section{Exclusion Criteria}

1. Children with known congenital anomalies of the kidney/urinary tract or having multiple anomalies like syndromic patients e.g. Down's syndrome

\section{Methods}

This was cross sectional survey conducted in Department of Pediatric Medicine, The Children's Hospital \& Institute of Child Health, Lahore with duration of Six months spanning from 20-5-2014 to 19-11-2014. Sampling technique was non probability, purposive with estimated sample size, calculated with $95 \%$ confidence level, 7\% margin of error with an expected VUR frequency of $22 \%$, is 140 children. ${ }^{8}$ After an informed consent, patients fulfilling the inclusion criteria were enrolled. Collected data was entered and analyzed using statistical software SPSS version 20. Mean and \pm SD was calculated for quantitative variables like age, number of episodes of urinary tract infections. Frequency tabulation and percentage was done for qualitative variables like vesicoureteral reflux in recurrent urinary tract infections. Data was stratified for age, gender and number of episodes of urinary tract infection. Chi-square test was applied post stratification with $p$-value $\leq 0.05$ considered as significant.

\section{Results}

In this study the mean age of all patients $(n=40)$ in this study was $5.64 \pm 2.35$ with age range of 8 years (minimum age $=2$ and maximum age $=0$ years). The mean number of episodes of urinary tract infection was $5.82 \pm 1.95$ with minimum and maximum number of urinary tract infection per years. (Table 1). When we stratified the data over age, gender and number of episodes of urinary tract infection we found that, among 35 patients with vesicoureteral reflux, there were $12(343 \%)$ patients who were $2-5$ years of age and $23(65.7 \%)$ patients were $6-10$ years of age. There was significant association between vesicoureteral reflux and age groups of the patients, p-value 0.004 . There was no significant association between vesicoureteral reflux and gender, $\mathrm{p}$-value $=0.523$. Likewise, there was no statistical association between vesicoureteral reflux and number of episodes of urinary tract infection, $\mathrm{p}$-value $=0.481$.

Table 1: Descriptive Statistics of Age (Years) and Number of Episodes of Urinary Tract Infection

\begin{tabular}{lccccc}
\hline & Mean & $\begin{array}{c}\text { Std. } \\
\text { Deviation }\end{array}$ & Range & Min. & Max. \\
\hline Age (years) & 5.64 & \pm 2.35 & 8 & 2 & 10 \\
$\begin{array}{l}\text { Number of episodes } \\
\text { of urinary tract }\end{array}$ & 5.82 & \pm 1.95 & 6 & 3 & 9 \\
infection & & & & & \\
\hline
\end{tabular}

Table 2: Frequency and Comparison of Vesicoureteral Reflux with Respect to Age (Years), Gender and Number of UTI Episodes Frequency Distribution of Vesicoureteral Reflux in Recurrent UTI Patients

\begin{tabular}{|c|c|c|c|c|}
\hline \multicolumn{2}{|l|}{ Yes } & \multicolumn{3}{|c|}{ No } \\
\hline \multicolumn{2}{|l|}{$35(25 \%)$} & \multicolumn{3}{|c|}{$105(75 \%)$} \\
\hline \multicolumn{5}{|c|}{$\begin{array}{l}\text { Comparison of Vesicoureteral Reflux with Respect to Age } \\
\text { (Years), Gender and Number of UTI Episodes }\end{array}$} \\
\hline & & \multicolumn{2}{|c|}{ Vesicoureteral reflux } & \multirow[t]{2}{*}{ p-value } \\
\hline & & Yes & No & \\
\hline \multirow[t]{2}{*}{ Age groups (years) } & $2-5$ & $12(34.3 \%)$ & $65(61.9 \%)$ & \multirow[t]{2}{*}{0.004} \\
\hline & $6-10$ & $23(65.7 \%)$ & $40(38.1 \%)$ & \\
\hline \multirow[t]{2}{*}{ Gender } & Male & $12(34.3 \%)$ & $30(28.6 \%)$ & \multirow[t]{2}{*}{0.523} \\
\hline & Female & $23(65.7 \%)$ & $75(71.4 \%)$ & \\
\hline \multirow{2}{*}{$\begin{array}{l}\text { Number of episodes } \\
\text { of urinary tract } \\
\text { infection }\end{array}$} & $3-6$ & $20(57.1 \%)$ & $67(63.8 \%)$ & \multirow[t]{2}{*}{0.481} \\
\hline & $7-9$ & $15(42.9 \%)$ & $38(36.2 \%)$ & \\
\hline
\end{tabular}




\section{Discussion}

If urinary tract abnormalities like vesicourethral reflux is diagnosed earlier in patients with repeated UTI the damage in kidney can be prevented either with prophylactic antibiotics or with corrective surgery. ${ }^{9}$ Symptoms for UTI in older children can be of urinary origin but in younger kids symptoms are usually nonspecific and sometime in infants they are difficult to observe. Urine dipstick analysis is important for ruling out of UTI in patients having low level of clinical suspicion. Although Urine culture is gold standard for diagnosis of UTI in children having high suspicion clinically, cloudy urine, positive leukocyte esterase or positive nitrate activity in case of urine dipstick analysis. ${ }^{10}$

For diagnosis of repeated UTIs related morbidities, we need detailed history, physical examination, renal as well as bladder sonography urine analysis and culture and contrast cystography, beside assessing other risk factors like bacterial virulence, antibiotic resistance. ${ }^{11}$

$3 \%$ of girls in prepuberty phase and $1 \%$ of boys in prepuberty phase are diagnosed with UTI. The incidence for urine infection in childhood and infancy is high and also influenced by gender and age. ${ }^{12}$ Average age for subjects was $27.15 \pm 20.72$ months. ${ }^{13} 80$ (81.8 $\%)$ males along with $18(18.2 \%)$ females were included. Most subjects were of age 01.00 to 24.66 months in one study. ${ }^{13}$ In our study average age of subjects was $5.64 \pm 2.35$ yrs. There were $42(30 \%)$ males and $98(70 \%)$ females in this study with male to female proportion 1:2.33.

Risk of recurrent UTI is high in children anomalies like vesicoureteral reflex and neurogenic bladder or with poor hygiene habits. ${ }^{14}$ In this study average number for episodes of UTI was $5.82 \pm 1.95$ with maximum and minimum number of UTI per years.

Primary vesicoureteral reflux is congenital with normal functioning of lower urinary tract, on other hand secondary vesicoureteral reflux is due to obstructive cause like posterior ureteral valve or neurogenic bladder. ${ }^{15}$ Precise frequency for vesicoureteral reflux is not known because several children are asymptomatic but vesicoureteral reflux frequency is much higher in children suffering from repeated UTI $15-70 \%{ }^{13,15,16,17}$

In this study stratification of data was done for gender, age and episodes of UTI, we observed that in
35 patients suffering from vesicoureteral reflux 12(34 $\%$ ) patients are with age group ( 2 to 5 years), whereas $23(65.7 \%)$ of are with age group ( 6 to 10 years). There is strong relationship between to the age and vesicoureteral reflux (p-value 0.004). There is no statistically significant relationship between gender, number of urine tract infections with vesicoureteral reflux.

We made conclusion from our study that congenital abnormalities of urine tract must be looked for in any age group of children presenting with repeated UTI, irrespective of gender and number of urine tract infections. Vesicoureteral reflux should be promptly suspected and treated accordingly, in order to prevent renal scarring. ${ }^{18}$

\section{Conclusion}

We found significant correlation between vesicoureteral reflux and repeated urinary tract infections. Children with repeated urinary tract infections should be investigated thoroughly to address underlying cause, in order to prevent irreversible renal damage and long-term complications.

\section{Conflict of Interest: None}

\section{References}

1. Korbel L, Howell M, Spencer JD. The clinical diagnosis and management of urinary tract infections in children and adolescents. Paediatrics and international child health. 2017 Oct 2;37(4):273-9.

2. Williams G, Craig JC. Long-term antibiotics for preventing recurrent urinary tract infection in children. Vol. 2019, Cochrane Database of Systematic Reviews. John Wiley and Sons Ltd; 2019.

3. Elder JS. Urinary Tract Infections. Nelson Textbook of Pediatrics. 21st ed. Philadelphia: Elsevier 2019; p. 10943-10967.

4. Nelson CP, Hoberman A, Shaikh N, Keren R, Mathews R, Greenfield SP, et al. Antimicrobial resistance and urinary tract infection recurrence. Pediatrics. 2016 Apr 1;137(4).

5. Lee JN, Byeon KH, Woo MJ, Baek HS, Cho MH, Jeong SY, et al. Susceptibility of the index urinary tract infection to prophylactic antibiotics is a predictive factor of breakthrough urinary tract infection in children with primary vesicoureteral reflux receiving continuous antibiotic prophylaxis. J Korean Med Sci. 2019 Jun 1;34(21).

6. Kariyappa P, Reddy SC, Mavinahalli AS, Rao US. Urinary tract abnormalities in children with first uri- 
nary tract infection. Indian Journal of Child Health. 2020 Aug 24;7(8):337-9.

7. Storme O, Tiran Saucedo J, Garcia-Mora A, DehesaDávila M, Naber KG. Risk factors and predisposing conditions for urinary tract infection. Therapeutic advances in urology. 2019 Mar;11: 1756287218814382

8. Doğan ÇS, Koyun NS, Aksoy GK, Çekiç B, Savaş M, Çomak E. Delayed diagnosis of primary vesicoureteral reflux in children with recurrent urinary tract infections: Diagnostic approach and renal outcomes. Turkish journal of urology. $2018 \mathrm{Nov}$;44(6):498.

9. Williams G, Craig JC. Long-term antibiotics for preventing recurrent urinary tract infection in children. Cochrane database of systematic reviews. 2019(4).

10. Okarska-Napierała M, Wasilewska A, Kuchar E. Urinary tract infection in children: Diagnosis, treatment, imaging-Comparison of current guidelines. Journal of pediatric urology. 2017 Dec 1;13(6):56773.

11. Leung AK, Wong AH, Leung AA, Hon KL. Urinary tract infection in children. Recent Patents on inflammation \& allergy drug discovery. 2019 May 1; 13(1): 2-18.

12. Lee RK, Pradere B. A new paradigm in treating urinary infections?. Current Opinion in Urology. 2020 Nov 1;30(6):832.

13. Lal S, Abbasi A, Shaikh AG. Vesicoureteral reflux in children up to 5 years of age with treated urinary tract infections in a tertiary care hospital. Medical Channel. 2013;19(3):31-4.

14. Doern CD, Richardson SE. Diagnosis of urinary tract infections in children. Journal of clinical microbiology. 2016 Sep 1;54(9):2233-42.

15. Nelson C. Pediatric Vesicoureteral Reflux. Medscape. [Online avaiable from]: http:// emedicine. medscape. com/article/1016439-overview\#a5. Accessed on June 2015.

16. Larcombe J. Urinary tract infection in children. Clinical evidence. 2006:[Online avaiable from]: http://europepmc.org/abstract/med/19454098. Accessed June 2015.

17. Williams G, Hodson EM, Craig JC. Interventions for primary vesicoureteric reflux. Cochrane database Syst Rev. 2019Feb 20;2:CD001532.

18. Shaikh N, Mattoo TK, Keren R, Ivanova A, Cui G, Moxey-Mims M, Majd M, Ziessman HA, Hoberman A. Early antibiotic treatment for pediatric febrile urinary tract infection and renal scarring. JAMA pediatrics. 2016 Sep 1;170(9):848-54.

\section{Author's Contribution}

AI: Data Collection

SAM: Conceptualization of Project, Writing of Manuscript

ZF: Literature Search

QH: Drafting 